prognosis and the overall survival (OS) were performed using the Cox proportional hazard model.

Results Multivariate analyses show that the number of the lesions ( $\mathrm{P}=0.006$, IDDF2021-ABS-0020 Figure 1. OS curves according to tumour location (Cox proportional hazards model)), the lymph nodes metastasis $(\mathrm{P}<0.001$, IDDF2021ABS-0020 Figure 2. OS curves according to tumour type (primary or metastatic) (Cox proportional hazards model)), the overall treatments $(\mathrm{P}=0.020)$, and the surgery $(\mathrm{P}=0.025)$ are the independent factors that may affect the prognosis of patients with gastrointestinal mucosal melanomas. What's more, this is a rare study to analyze the association between the certain expression of immunohistochemical indexes and the OS of patients with gastrointestinal mucosal melanomas. However, we did not find it significantly associated with the OS of our patients. All the results shown above need further exploration.

Conclusions The condition of primary or metastatic tumors, the anatomic sites in the gastrointestinal tract, and the lymph nodes metastasis may be the independent factors that affect the prognosis of patients with gastrointestinal mucosal melanomas. This study is expected to provide some clues for future exploration which will help clinicians improve the accuracy of judging prognosis.

\section{IDDF2021-ABS-0021 BETTER BOWEL PREPARATION - APPROPRIATE PREOPERATIVE TIME AND GRAPHIC GUIDANCE TO STRENGTHEN EDUCATION BEFORE EXAM}

Jiachen Sun*, Jiancong Hu, Yongpeng Chen. The Sixth Affiliated Hospital, Sun Yat-sen University, China

\subsection{6/gutjnl-2021-IDDF.109}

Background Inadequate bowel preparation (BP) was considered as a major obstacle for successful colonoscopy, which leads to the lower rate of adenoma and polyp detection, increasing related costs, lower cecal intubation rate, and the possibility of repeated examination. We performed a secondary analysis of a colorectal cancer screening program to explore the factors which could improve the bowel preparation quality before colonoscopy.

Methods 738 patients were included in this study. Divided into graphic group $(n=242)$ and word group $(n=496)$, according to their education of BP, and 6-8 hours (group 1, $\mathrm{n}=106$ ), 9-12 hours (group 2, $\mathrm{n}=228$ ) and 13-17 hours (Group 3, $\mathrm{n}=402$ ) according to the interval between BP and colonoscopy. All patients were scored BP according to the BBPS score during the exam.

Results The BP of graphic group was significantly better than that of word group $(P<0.001)$. The score of BP of the Group 1 and Group 2 were both significantly higher than that of Group $3(P<0.001)$. After adjustment, the score of BP of the Group 1 and Group 2 were still both significantly higher $(P=0.012$ and $P=0.032)$ (IDDF2021-ABS-0021 Figure A. The relationship between BBPS and interval time of nonadjustment B) (IDDF2021-ABS-0021 Figure B. The relationship between BBPS and interval time after adjustment for gender, age, smoking history, drinking history, family history of colorectal cancer, family history of cancer, type of laxatives, education methods).

Conclusions Patients who use graphic version of the education manual were getting better bowel preparation and the BP is better starting in 6-12 hours and best in 6.5 hours before the exam.

\section{IDDF2021-ABS-0023 EFFECTIVITY OF MOIST EXPOSED BURN OINTMENT (MEBO) AND THE ROLE ON REDUCING THE CHEMOTHERAPY INTERRUPTION OF CAPECITABINE ASSOCIATED HAND FOOT SYNDROME ON STAGE III COLORECTAL ADENOCARCINOMA}

${ }^{1}$ Budhi Ida Bagus*, ${ }^{2}$ Agustriani Nunik, ${ }^{3}$ Ermawan Rieva, ${ }^{2}$ Suwardi Suwardi, ${ }^{4}$ Sungkar Amru, ${ }^{5}$ Saadhi Ikhdin R, ${ }^{6}$ Mastini Ida Ayu Kade, ${ }^{1}$ Metria Ida Bagus, ${ }^{7}$ Setyawati Ida Ayu. ${ }^{1}$ Department of Surgery, Sebelas Maret University, Indonesia; ${ }^{2}$ Pediatric Surgery Department, Sebelas Maret University, Indonesia; ${ }^{3}$ Orthopaedic Surgery Department, Sebelas Maret University, Indonesia; ${ }^{4}$ Plastic Surgery Department, Sebelas Maret University, Indonesia; ${ }^{5}$ Department of Surgeny, Moewardi General Hospital, Indonesia; ${ }^{6}$ Clinical Pharmacy Department, Moewardi General Hospital, Indonesia; ${ }^{7}$ Medical Faculty, Pendidikan Ganesha University, Indonesia

\subsection{6/gutjnl-2021-IDDF.110}

Background A common adverse effect of the fluoropyrimidine chemotherapy agent capecitabine is Hand-foot syndrome (HFS), known as a palmoplantar erythrodysesthesia. Hand-foot syndrome of any grade is reported to affect $43 \%$ to $71 \%$ of patients treated with single-agent capecitabine chemotherapy.
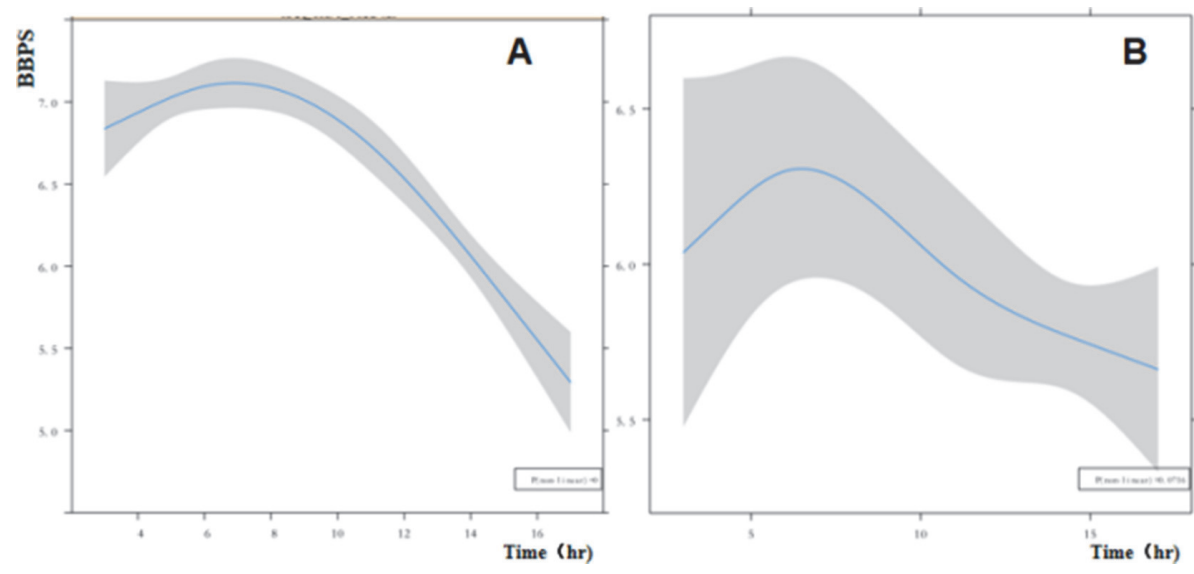